\title{
Healthcare professional-led interventions on lifestyle modifications for hypertensive patients - a systematic review and meta- analysis
}

Indre Treciokiene ${ }^{1,2^{*}}$ (D) , Maarten Postma ${ }^{1,3,4}$, Thang Nguyen ${ }^{5}$, Tanja Fens ${ }^{1}$, Jurgis Petkevicius ${ }^{6}$, Raimondas Kubilius ${ }^{6}$, Jolanta Gulbinovic ${ }^{2}$ and Katja Taxis ${ }^{1}$

\begin{abstract}
Background: About 0.9 billion people in the world have hypertension. The mortality due to hypertension increased dramatically over the last decades. Healthcare professionals should support patients with hypertension to modify their lifestyle to decrease blood pressure, but an overview of effective lifestyle interventions is lacking. The aim of this study was to determine whether healthcare professional-led interventions on lifestyle modifications are effective in lowering blood pressure in patients with hypertension.

Methods: A systematic literature review following the PRISMA guidelines was conducted. PubMed, EMBASE and CINAHL databases were searched for randomized control trials (RCTs) of interventions on lifestyle modifications of hypertensive patients which were performed by healthcare professionals (physician, nurse, pharmacist) and which reported blood pressure measurements. Papers were reviewed by two reviewers and analysed using Cochrane software Revman 5.4. In a meta-analysis difference in systolic blood pressure (SBP), diastolic blood pressure (DBP) and the percentage of patients with controlled blood pressure (BP) was analysed.

Results: In total, 34 clinical trials reporting on 22,419 patients (mean age 58.4years, 49.14\% female, 69.9\% used antihypertensive medications) were included. The mean difference SBP was $-4.41 \mathrm{mmHg}(95 \% \mathrm{Cl},-5.52$ to -3.30$)$ and the mean difference DBP was $-1.66 \mathrm{mmHg}(95 \% \mathrm{Cl}-2.44$ to -0.88$)$ in favor of the intervention group vs usual care. Fifty-six percent of patients achieved BP control in the intervention group vs $44 \%$ in usual care, $\mathrm{OR}=1.87(95 \% \mathrm{Cl}, 1.51$ to 2.31 ).

Conclusion: Healthcare professional-led interventions were effective. Patients achieved almost $5 \mathrm{mmHg}$ decrease of SBP and more patients achieved BP control. The results suggest that efforts are needed for widespread implementation.
\end{abstract}

Keywords: Hypertension, Blood pressure, Non-pharmacological intervention, Lifestyle, Health care professionals 


\section{Background}

Cardiovascular diseases (CVDs) remain the most common cause of death worldwide, causing 17.3 million (31.5\%) deaths globally [1]. One of the most important risk factors to develop CVDs is hypertension [1]. Globally WHO reports suggest that 1 in 5 adults had raised blood pressure [2]. In the same time period, the prevalence of hypertension among US adults of 20 years of age or older was estimated to be even $34.0 \%$ [3]. Death rates due to hypertension have increased worldwide and are associated with high costs [4]. In the U.S.A. the annual national spending on hypertension increased significantly from $\$ 58.7$ billion to $\$ 109.1$ billion from 2000 to 2001 to $2012-$ 2013 [5] and is associated with about $\$ 131$ billion per year in population-level expenditures [6].

Unhealthy diet, physical inactivity and obesity increase the risk of developing hypertension [7]. Lifestyle change is a key component in the cardiovascular risk management and essential in decreasing blood pressure [8-10]. Studies evaluating lifestyle modifications such as weightreducing diets, regular exercise as well as restricted alcohol and salt intake showed positive effects on blood pressure [11]. In a systematic review, Dickinson et al. assessed the effects of the different lifestyle modifications. Improved diet resulted in a mean reduction of systolic blood pressure (SBP) of $-5.0 \mathrm{mmHg}(95 \% \mathrm{CI}$, -7.0 to -3.1$)$, aerobic exercise $-4.6 \mathrm{mmHg}(95 \% \mathrm{CI}$, -7.1 to -2.0$)$, alcohol restriction $-3.8 \mathrm{mmHg}(95 \% \mathrm{CI}$, -6.1 to -1.4$)$ and sodium restriction $-3.6 \mathrm{mmHg}(95 \%$ $\mathrm{CI},-4.6$ to -2.5 ) [12]. Healthcare professionals have an important role in supporting patients in achieving such lifestyle alterations to improve blood pressure control. Previous systematic reviews have shown that pharmacist[13] and nurse- [14] led interventions can be successful in improving blood pressure control, but those studies did not focus on interventions of lifestyle modification. In another systematic review, it was shown that physician-led interventions result in significant weight losses, but this study did not assess hypertension [15]. An overview of effective lifestyle interventions which can be performed by healthcare professionals is lacking. Therefore, the aim of this study was to determine whether healthcare professional-led interventions on lifestyle modifications are effective in lowering blood pressure in patients with hypertension.

\section{Methods}

A systematic literature review and meta-analysis following the PRISMA guidelines for reporting was performed [16]. A literature search for studies evaluating interventions on lifestyle modifications in patients with hypertension was conducted.

\section{Inclusion and exclusion criteria}

Included studies:

- Were randomized controlled clinical trials (RCTs);

- Involved patients with a diagnosis of hypertension or with an elevated blood pressure above $140 / 90 \mathrm{mmHg}$ or 130/80 for patients with diabetes [17];

- Evaluated an intervention led by a healthcare professional which consisted of one or more individual consultations on lifestyle modification, health promotion or non-pharmaceutical management, targeting blood pressure.

Excluded studies:

- Were non-English articles;

- Interventions performed in group sessions;

- Consisted of pharmacological interventions only;

- Interventions that included less than 10 patients in either intervention or control group

Studies which compared two different approaches of lifestyle intervention were not in the scope of this review. These were for example studies which assigned patients assigned to sports activities or diet management. Those studies compared the effects of specific sports or diets rather than investigate effects of the provider-led interventions.

Healthcare professionals were defined as those with extensive knowledge including university-level study leading to the award of a first degree or higher qualification [18], in most cases - physicians, nurses and pharmacists. Studies that included less than 10 patients were excluded as they would be more heterogeneous and a high possibility of selection bias in a small study could occur [19]. Interventions were defined as tailored when the contact with a healthcare professional was intensified or de-intensified, based on the patient's blood pressure data.

\section{Outcome measures}

Outcomes of the review were the difference in systolic and diastolic blood pressure between intervention and control groups, and the difference in the proportion of patients achieving BP control.

\section{Data collection and analysis}

The systematic review protocol was created. Search keys for PubMed, Embase and Cinahl were built; additionally, the references of indicated papers were searched. The PubMed search key could be found in the Additional file 1 .

The search was carried out on the 18th of May 2020. 
Two researchers - I.T. and J.P. - independently reviewed titles, abstracts and full articles. Reviewers separately reviewed the extracted data on number of patients, the duration of intervention and follow-up, intervention components as well as baseline and followup blood pressure measurements and discussed the discrepancies. In case of discrepancies, cases were discussed with a third reviewer K.T. If any data required for the analyses was missing in the retrieved articles, the authors were contacted.

Two researchers - I.T. and T.F. - assessed the risk of bias using the Cochrane risk of bias tool [20]. Non-pharmacological interventions may introduce more biases as the participants and personnel cannot always be blinded due to the nature of the interventions. Baseline characteristics of included patients may have an impact on the overall assessment of biases as well. Nine criteria for the assessment of risk of bias were used, including random sequence generation, allocation concealment, similarity of baseline outcome measurements, similarity of baseline characteristics, blinding of outcome assessment, incomplete outcome data, contamination, selective reporting and other biases reported by the investigators. Biases were assigned to one of the three categories - low risk, unclear risk and high risk. Studies having 4 or more criteria scoring high risk/unclear risk were categorized as having an overall high risk of bias.

Meta-analyses by RevMan 5.4 using a random effects analysis model was performed. The mean difference in systolic and diastolic blood pressure between the intervention and the usual care group was calculated, as well as the percentage of patients who achieved BP control in the intervention and the usual care group. The odds ratio for BP control were determined.

To avoid unit-of-analysis errors for cluster-randomized controlled trials (cRCTs) in which incorrect statistical analyses were conducted, an approximate analysis based on inflating standard errors was performed. Before entering data into RevMan the standard error of the effect estimate (from an analysis that does not take clustering into account) was multiplied by the square root of the design effect. The design effect was determined as $1+(\mathrm{M}-1) \mathrm{ICC}$, where $\mathrm{M}$ is the average cluster size and ICC - the intracluster correlation coefficient. The common design effect across the intervention groups was assumed. If the ICC was not available in the published report, the mean ICC from other included cRCTs was used. Sensitivity analyses for RCT comparing the data as presented and taking the intracluster correlation coefficient into account was performed.

If the study included more than two intervention arms and no control or usual care group, the intervention closest to usual care was considered as usual care. If the studies had two treatment arms and a usual care group, only the treatment arm that had lifestyle modification or health promotion provided by health care professional was included into meta-analyses. This approach was chosen in line with recommendations by Cochrane to overcome a unit-of-analysis error [20].

Means and standard deviations from a relevant intervention or a usual care group were pooled. If standard deviation (SD) was not provided in the study report, it was calculated with the "Cochrane collaboration finding standard deviations calculator" from other standard errors or confidence intervals given. If the data was missing or clarification needed the authors were contacted. If it was not possible to obtain SD, the mean SD of the included studies was used.

Heterogeneity according to the approach described in the Cochrane Handbook was assessed [20]. The $\mathrm{I}^{2}$ statistic to assess heterogeneity was used, considering heterogeneity to be statistically significant if the $p$ value was less than 0.05 . The interpretation of the $\mathrm{I}^{2}$ statistic was followed, $0-30 \%$ might not be important, $30-60 \%$ may represent moderate heterogeneity, $50-75 \%$ may represent substantial heterogeneity and $75-100 \%$ represents considerable heterogeneity. Since it was assumed that clinical and methodological diversity within the studies may occur, it was agreed that $\mathrm{I}^{2}$ value between 30 and $60 \%$ represents moderate heterogeneity, and $\mathrm{I}^{2}$ over $60 \%$ represents substantial heterogeneity.

\section{Data synthesis and subgroup analysis}

Intervention effects for dichotomous data were calculated as odds ratio with the $95 \%$ confidence intervals. For continuous data, the mean differences with the 95\% confidence intervals were calculated. Extreme outliers were excluded from the analysis, a sensitivity analysis including the outliers was performed.

Several subgroup analyses were carried out as recommended [21]. Subgroup analyses based on place the outcome blood pressure was taken (home or office), the duration of an intervention (under 6 months or longer than 6 months), by the type of healthcare professional and the type of intervention (face to face vs via device and tailored vs not tailored intervention) were performed. In further subgroup analyses the effects in patients with baseline systolic blood pressure under and above $150 \mathrm{mmHg}$ were investigated. Finally, the effects of interventions which included medication adherence tool or antihypertensive medications review were investigated.

\section{Results}

The description of studies

Eight thousand seven hundred eighty-one articles were retrieved (Fig. 1). 


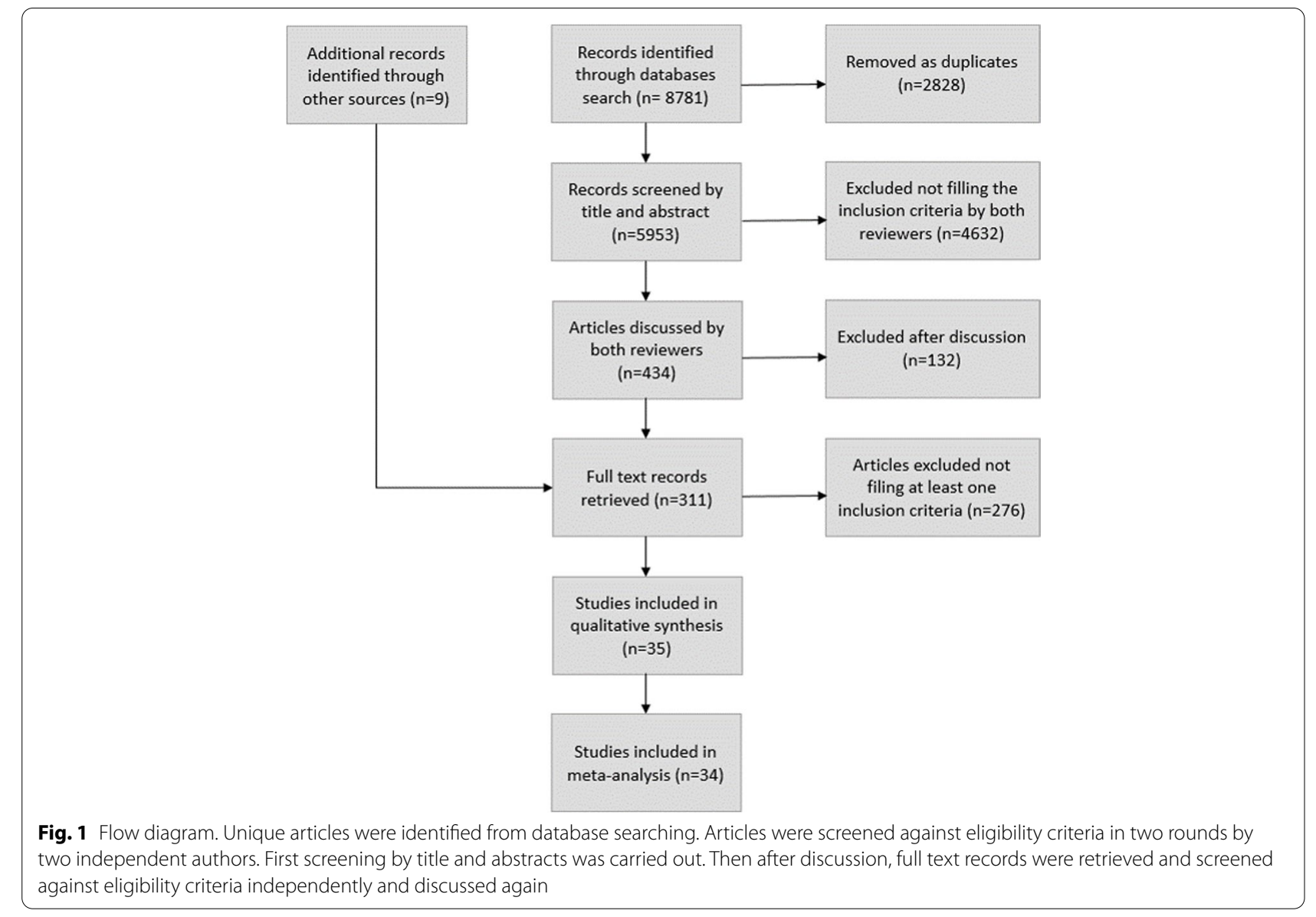

Thirty-five clinical trials were included in the review. In the studies, 22,715 patients were randomized; the mean age was 58.1 years, $49 \%$ were female, $69 \%$ used antihypertensive medications. At least $23 \%$ of included patients were diagnosed with diabetes.

Of the included studies, 30 were individual randomized controlled trials and 5 were cluster randomized trials. Twenty studies were carried out in the United States [22-41], 4 in Europe [42-45], 2 in China [46, 47] 1 in Canada [48], Australia [49], Mexico [50], Taiwan [51], Pakistan [52], Thailand [53], South Africa [54], Japan [55] and India [56]. For 20 studies [24, 25, 27-29, 31-33, 38, $41,43,45-51,53-56]$ a follow-up was completed within 6 months, in the remaining studies a follow-up was from 6 to 24 months (Table 1 ).

In all the studies, lifestyle modification was addressed. Two interventions were performed in community pharmacies [32, 48] one in pharmacy and primary care [53] all other studies were performed in primary care practices or outpatient centers of hospitals. In 16 studies the advice on dietary/sodium restriction was given $[24,28$, $29,34,35,37,41,42,45,46,49,50,53-56]$. Twenty studies addressed dietary/weight loss/dietary approaches to stop hypertension (DASH) [23, 24, 27, 31, 34-38, 40-42,
$45,47,49,50,53-56]$. Recommendations on alcohol consumption were given in 14 studies [24, 28, 34, 35, 41-43, $45-47,49,53,55,56]$. Fourteen studies included smoking cessation [23, 24, 31, 34-36, 42, 45-47, 49, 53, 55, 56]. Exercise/physical activity was recommended in 20 studies $[23,24,28,29,31,34,36,37,41,42,45-47,49-51$, 53-56]. Education on home blood pressure monitoring was provided and home BP devices were given in 13 studies [22, 24-26, 28, 31, 32, 34-37, 39, 55]. Seven studies included tailored interventions [25, 28, 31, 35, 37, 39, 46].

Healthcare professionals were specifically trained to give the intervention in 13 studies [22, 24, 29, 36-38, $41-43,46,47,50,52]$. Thirteen studies included a medication review in addition to the lifestyle interventions. Those medication reviews were performed by the interventionist or if needed by a healthcare professional the participant was referred to. In those studies recommendations/changes or referrals for changes on antihypertensive medications or regimens were performed if needed, alongside with the lifestyle modification intervention $[23,25,26,28-30,32,35,39,46$, $48,53,55]$. In 11 studies adherence improvement was additionally implemented [23, 27, 28, 30, 41, 44, 47, 52-55]. Techniques such as pill count, patient diary, 


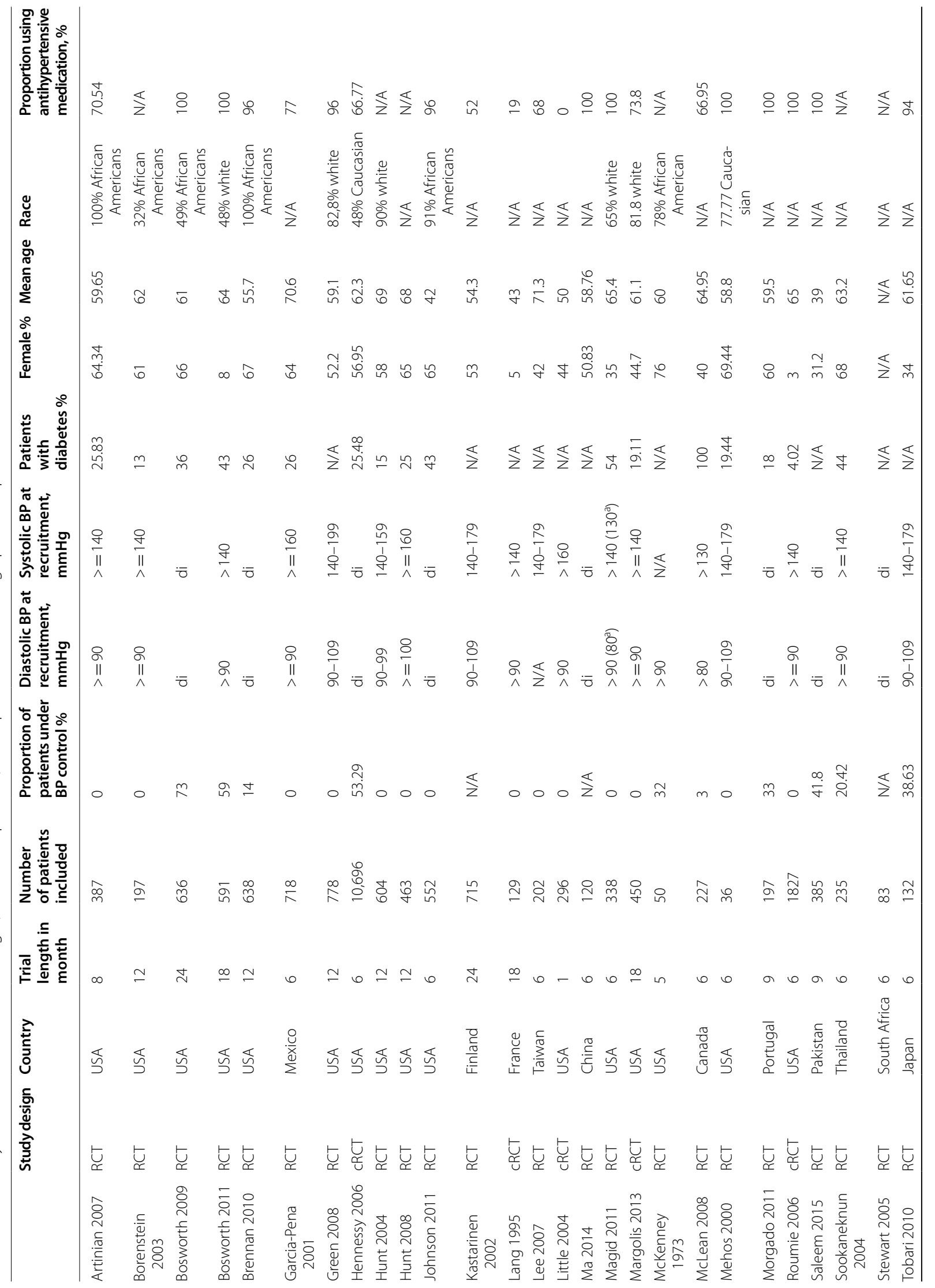




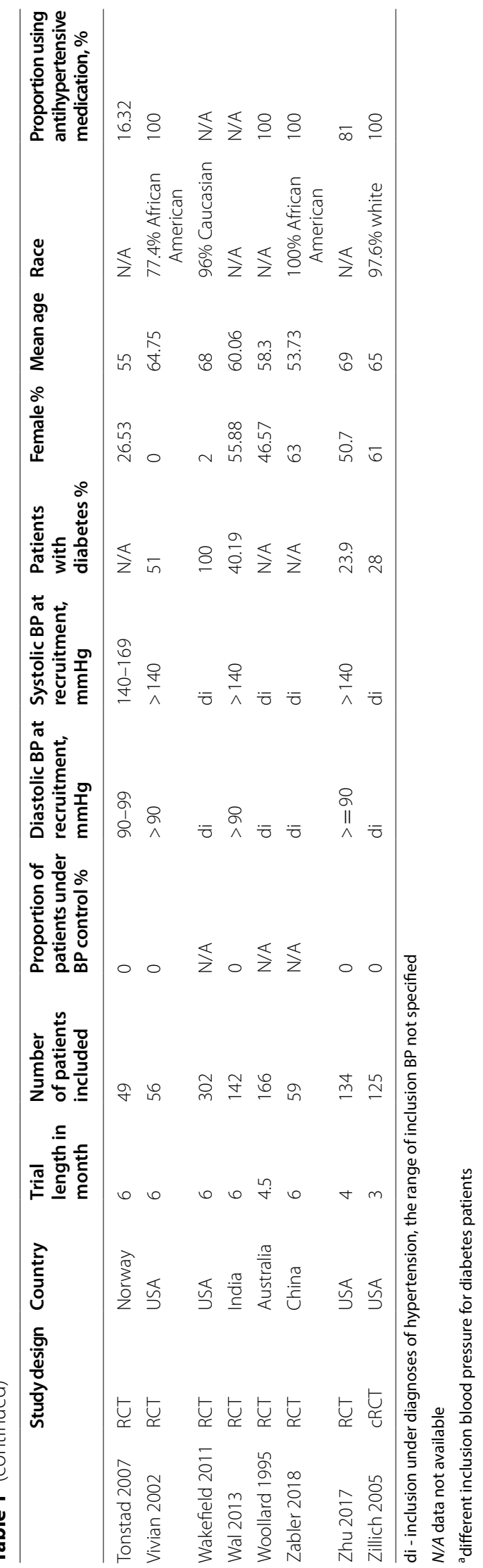


assessment with a questionnaire or data on adherence, obtained from the pharmacy and discussed with the patient, were used. In other studies, medication adherence was emphasized or was not mentioned at all. A summary of components of the interventions is provided in Table 2.

The authors of five studies were contacted to obtain missing outcome data. Four responses were received. One study was excluded from the meta-analyses as the missing data could not be obtained. Thirty-four studies contained sufficient data to be included in the metaanalyses. Twenty two thousand four hundred nineteen patients with mean age of 58.4 years where randomized in those studies. Forty-nine point fourteen percent of patients were female, $69.97 \%$ used antihypertensive medications.

The risk of bias of the studies that were included into meta-analyses was evaluated. Nine studies were considered as low in the overall assessment of bias, 25 as high (Fig. 2).

Contamination was possible when healthcare professionals were allocated within the same clinic or practice; in this case the communication between intervention and control professionals as well as patients was possible. In the cluster randomized trials with the allocation by an institution or a practice, this risk was prevented. Other risks provided by the authors were also common. The other risks of biases reported were not taking clustering into account [26, 32, 43], selfselection biases [36] labelling, that might have caused the increased care by a physician [53] only highly motivated [42] or highly educated patients included [37] language literacy [39] real world barriers [41] etc.

\section{Systolic blood pressure}

The mean difference of the SBP between the intervention group and the usual care group was $-4.41 \mathrm{mmHg}$ (95\% CI, -5.52 to -3.30 ). Patients with SBP higher than $150 \mathrm{mmHg}$ at baseline showed better response to intervention than patients with baseline SBP lower or equal to $150 \mathrm{mmHg}$. The mean difference SBP was $-5.66 \mathrm{mmHg}(95 \% \mathrm{CI},-7.61$ to -3.71$)$ and $-3.35 \mathrm{mmHg}$ (95\% CI, -4.43 to -2.26$)$ compared to the usual care group respectively $(P=0.04)$ (Fig. 3$)$.

There were no statistically significant differences in the mean reduction of SBP in the sub analysis by the type of a healthcare professional (Fig. 4).

There were also no statistically significant differences in the subgroup analyses by the duration of an intervention, the place of BP measurement, whether the interventions were tailored or not and whether the interventions contained a component addressing medication adherence (Table 3).

\section{Diastolic blood pressure}

Measurements of diastolic blood pressure were provided in 32 studies. Analyses of intervention studies showed that DBP decreased by $1.66 \mathrm{mmHg}(95 \%$ CI, -2.44 to -0.88$), \mathrm{I}^{2}=63 \%$. Heterogeneity of the included studies was too high to perform a subgroup meta-analysis.

\section{Blood pressure control}

Seventeen studies provided data on the proportion of patients achieving BP control. Fifty-six percent of patients achieved BP control in an intervention group vs $44 \%$ in a usual care group, OR $=1.87$ (95\% CI, 1.51 to 2.31 ).

Subgroup analyses revealed that better BP control was achieved when the baseline systolic blood pressure was over $150 \mathrm{mmHg}(P=0.04)$. Subgroup analyses showed no differences in BP control when different intervention methods or components were used (Table 4). We could not perform subgroup analyses on BP control effect by the place of a BP measurement as the final BP was measured at home only in two studies [36, 55].

\section{Discussion}

\section{Summary}

Interventions were effective and helped to achieve $4.41 \mathrm{mmHg}$ decrease of SBP and $1.66 \mathrm{mmHg}$ decrease of DBP. Statistically better SBP results and better BP control were achieved in the studies where baseline SBP was higher than $150 \mathrm{mmHg}$. Considering that nearly $70 \%$ of the patients were already taking medications, the additional SBP lowering by $5 \mathrm{mmHg}$ might be the solution for a better hypertension control. Several reports support the clinical relevance of SBP reduction by $1-5 \mathrm{mmHg}$. SBP decrease of $1 \mathrm{mmHg}$ reduces the risk of stroke by $5 \%$ [57]. Stamler et al. showed that the reduction of SBP by $5 \mathrm{mmHg}$ is associated with a $7 \%$ lower risk of allcause mortality, 9\% lower risk of mortality due to coronary heart disease and 14\% lower risk of mortality due to stroke [58].

In subgroup analysis, there were no differences in SBP and BP control between tailored and not tailored interventions, the different healthcare professionals performing the intervention and interventions including vs excluding medication review related components. This suggests that none of the features that were investigated had a preeminent impact, but rather the intervention itself. To further investigate the combined effects of lifestyle changes and medication change and adherence management on hypertension, individual patient data would be needed. 


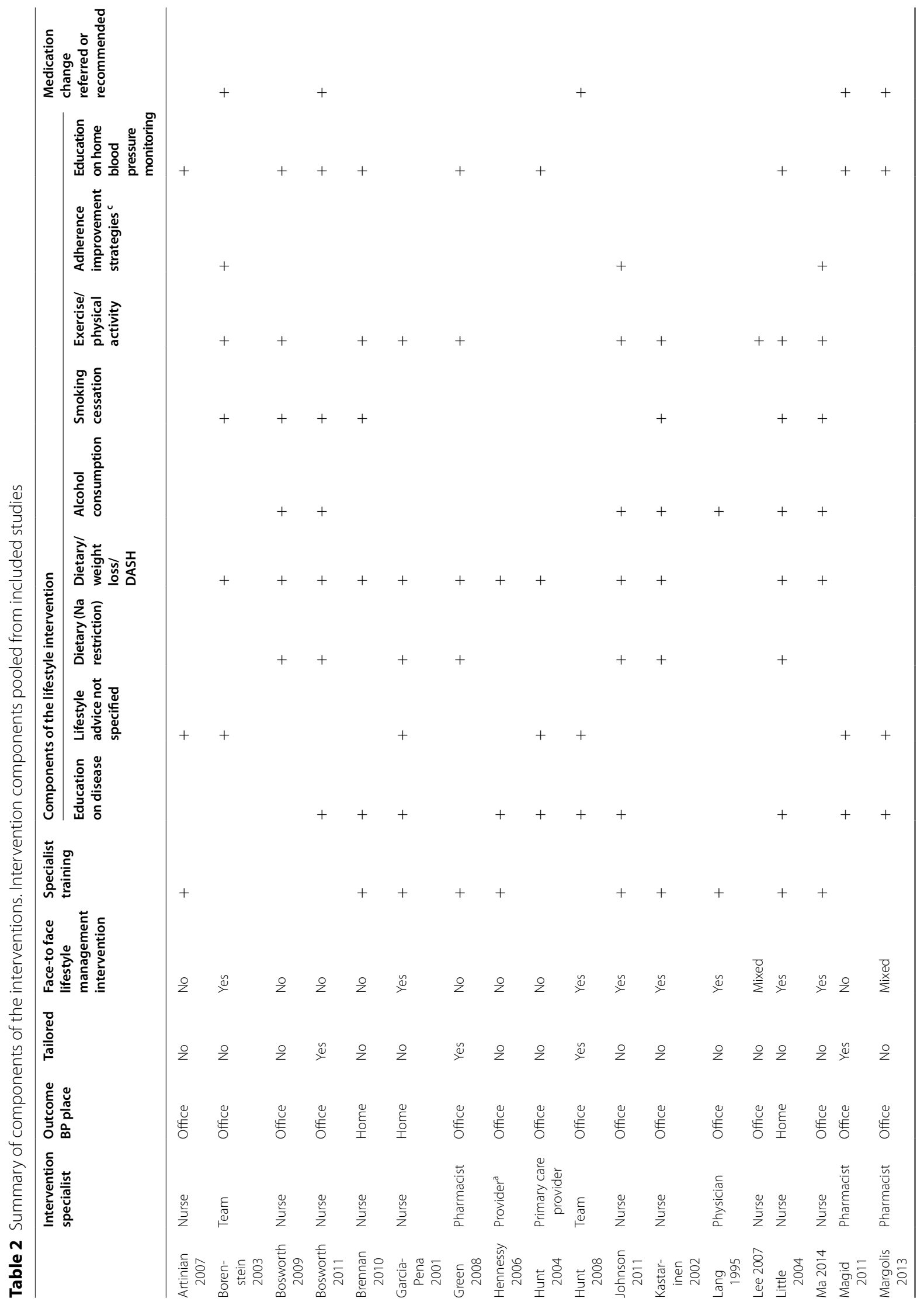




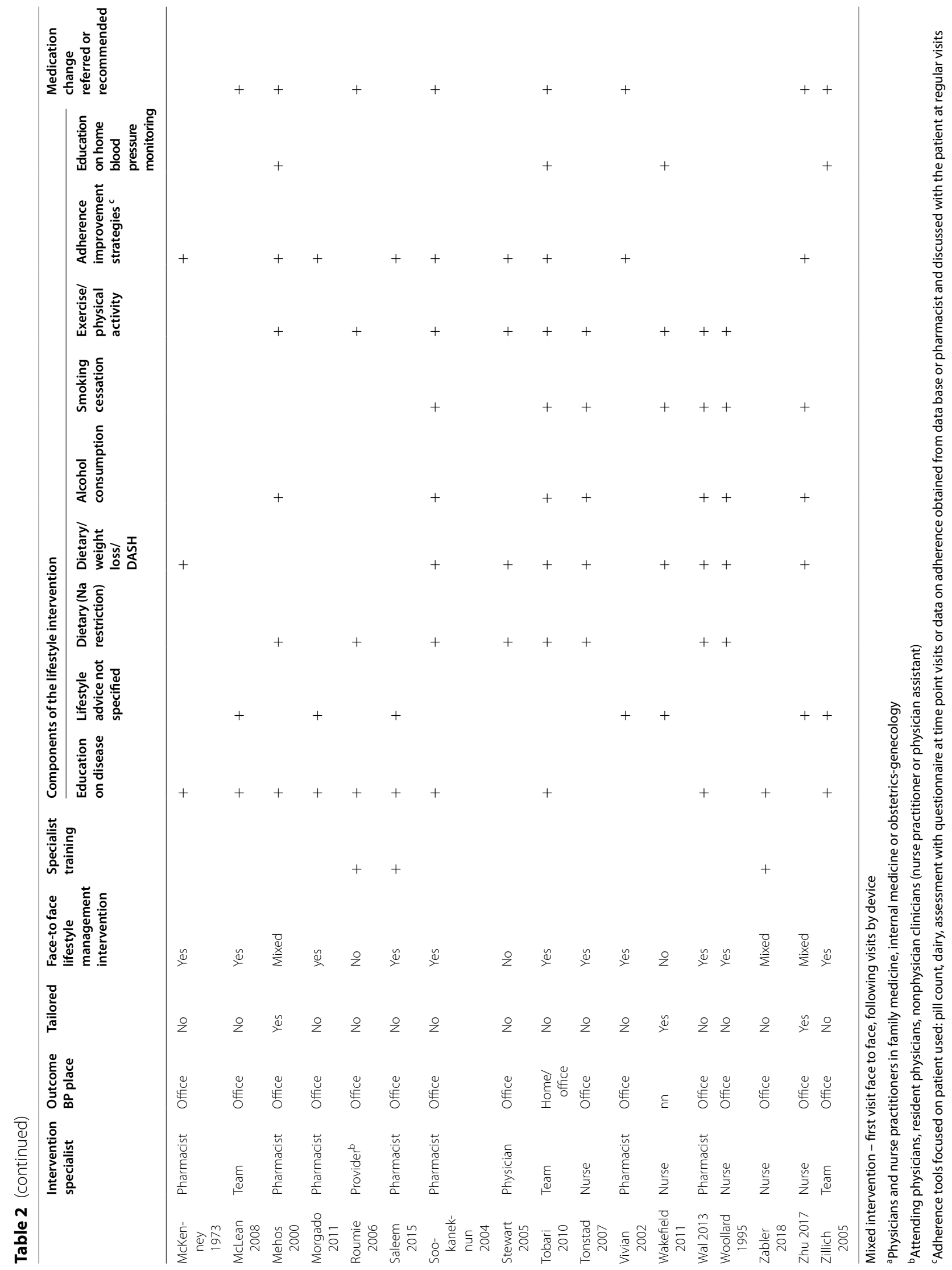




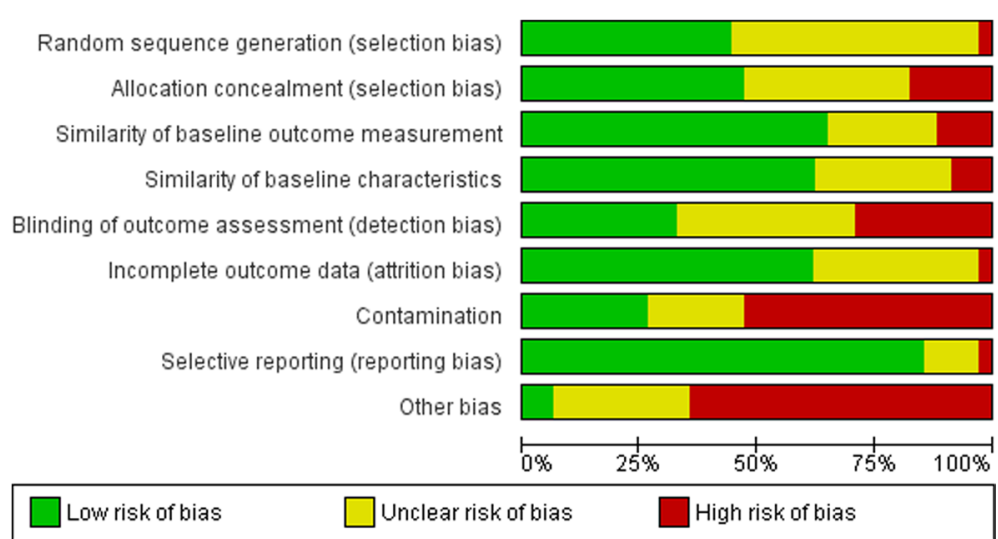

Fig. 2 Overall assessment of the biases of included studies. Nine criteria for the assessment of risk of bias were used. Biases were assigned to one of the three categories - low risk, unclear risk and high risk

\section{Strengths and limitations}

This study is the first systematic review on healthcare professional-led lifestyle interventions focusing on individual hypertensive patients.

Only two studies $[25,45]$ with blood pressure increase after an intervention were found. This might be that studies having a positive outcome were more likely to be published than those reporting negative results. However, sensitivity analysis with outliers showed that the estimate of the overall effect of interventions on BP was similar. As the heterogeneity was expected, the random effects analysis to allow for differences in the treatment effect from study to study was

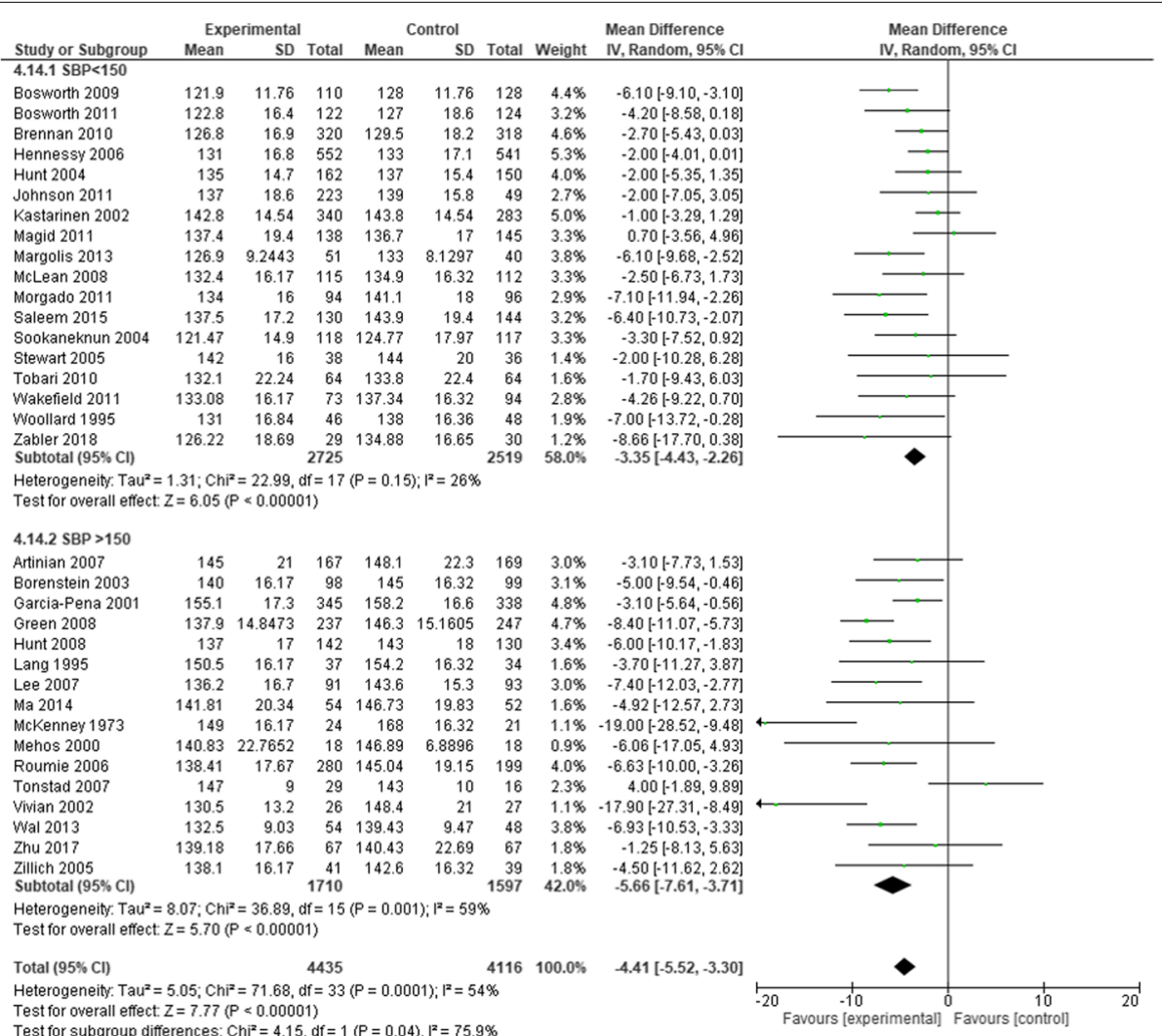

Fig. 3 Subgroup analyses of the effect of interventions by baseline systolic blood pressure. Legend: Forest plot shows difference in systolic blood pressure change between patients with baseline systolic blood pressure over $150 \mathrm{mmHg}$ versus patients with baseline systolic blood pressure lower than $150 \mathrm{mmHg}$; forest plot was created using RevMan 5.4; SBP - systolic blood pressure, Cl - confidence interval, SD - standard deviation; small green squares represent difference in SBP reduction of individual RCTs, horizontal lines show 95\% Cl, black diamonds represent difference in SBP reduction within subgroup and total. Statistically significant difference was found comparing subgroups $(P=0.04)$ 


\begin{tabular}{|c|c|c|c|c|c|c|c|c|c|c|}
\hline \multirow[b]{2}{*}{ Study or Subgroup } & & Experimental & \multicolumn{2}{|r|}{ Control } & \multirow[b]{2}{*}{ Total } & \multirow[b]{2}{*}{ Weight } & \multirow{2}{*}{$\begin{array}{l}\text { Mean Difference } \\
\mathrm{IV} \text {, Random, } 95 \% \mathrm{Cl}\end{array}$} & \multirow{2}{*}{\multicolumn{2}{|c|}{$\begin{array}{c}\text { Mean Difference } \\
\text { IV, Random, } 95 \% \mathrm{Cl}\end{array}$}} \\
\hline & Mean & SD & Total & Mean & SD & & & & & \\
\hline 4.13.1 Pharmacist & & & & & & & & & & \\
\hline Borenstein 2003 & 140 & 16.17 & 98 & 145 & 16.32 & 99 & $3.1 \%$ & $-5.00[-9.54,-0.46]$ & $\longrightarrow$ & \\
\hline Green 2008 & 137.9 & 14.8473 & 237 & 146.3 & 15.1605 & 247 & $4.7 \%$ & $-8.40[-11.07,-5.73]$ & - & \\
\hline Magid 2011 & 137.4 & 19.4 & 138 & 136.7 & 17 & 145 & $3.3 \%$ & $0.70[-3.56,4.96]$ & & - \\
\hline Margolis 2013 & 126.9 & 9.2443 & 51 & 133 & 8.1297 & 40 & $3.8 \%$ & $-6.10[-9.68,-2.52]$ & - & \\
\hline McKenney 1973 & 149 & 16.17 & 24 & 168 & 16.32 & 21 & $1.1 \%$ & $-19.00[-28.52,-9.48]$ & - & \\
\hline Mehos 2000 & 140.83 & 22.7652 & 18 & 146.89 & 6.8896 & 18 & $0.9 \%$ & $-6.06[-17.05,4.93]$ & & - \\
\hline Morgado 2011 & 134 & 16 & 94 & 141.1 & 18 & 96 & $2.9 \%$ & $-7.10[-11.94,-2.26]$ & - & \\
\hline Saleem 2015 & 137.5 & 17.2 & 130 & 143.9 & 19.4 & 144 & $3.2 \%$ & $-6.40[-10.73,-2.07]$ & - & \\
\hline Sookaneknun 2004 & 121.47 & 14.9 & 118 & 124.77 & 17.97 & 117 & $3.3 \%$ & $-3.30[-7.52,0.92]$ & & \\
\hline Vivian 2002 & 130.5 & 13.2 & 26 & 148.4 & 21 & 27 & $1.1 \%$ & $-17.90[-27.31,-8.49]$ & - & \\
\hline Wal 2013 & 132.5 & 9.03 & 54 & 139.43 & 9.47 & 48 & $3.8 \%$ & $-6.93[-10.53,-3.33]$ & $\rightarrow$ & \\
\hline Zillich 2005 & 138.1 & 16.17 & 41 & 142.6 & 16.32 & 39 & $1.8 \%$ & $-4.50[-11.62,2.62]$ & & \\
\hline Subtotal $(95 \% \mathrm{Cl})$ & & & 1029 & & & 1041 & $33.0 \%$ & $-6.46[-8.70,-4.22]$ & $\bullet$ & \\
\hline $\begin{array}{l}\text { Heterogeneity } \mathrm{Tau}^{2}= \\
\text { Test for overall effect }\end{array}$ & $\begin{array}{l}8.50 ; \mathrm{Chi}^{2} \\
\mathrm{Z}=5.66(\mathrm{~F}\end{array}$ & $\begin{array}{l}\begin{array}{l}2=28.17, d \\
P<0.0000\end{array}\end{array}$ & $\begin{array}{l}d f=11 \\
01)\end{array}$ & $(P=0.00$ & 03); $1^{2}=619$ & & & & & \\
\hline 4.13.2 Nurse & & & & & & & & & & \\
\hline Artinian 2007 & 145 & 21 & 167 & 148.1 & 22.3 & 169 & $3.0 \%$ & $-3.10[-7.73,1.53]$ & - & \\
\hline Bosworth 2009 & 121.9 & 11.76 & 110 & 128 & 11.76 & 128 & $4.4 \%$ & $-6.10[-9.10,-3.10]$ & - & \\
\hline Bosworth 2011 & 122.8 & 16.4 & 122 & 127 & 18.6 & 124 & $3.2 \%$ & $-4.20[-8.58,0.18]$ & & \\
\hline Brennan 2010 & 126.8 & 16.9 & 320 & 129.5 & 18.2 & 318 & $4.6 \%$ & $-2.70[-5.43,0.03]$ & -1 & \\
\hline Garcia-Pena 2001 & 155.1 & 17.3 & 345 & 158.2 & 16.6 & 338 & $4.8 \%$ & $-3.10[-5.64,-0.56]$ & $\rightarrow$ & \\
\hline Johnson 2011 & 137 & 18.6 & 223 & 139 & 15.8 & 49 & $2.7 \%$ & $-2.00[-7.05,3.05]$ & $\rightarrow$ & \\
\hline Kastarinen 2002 & 142.8 & 14.54 & 340 & 143.8 & 14.54 & 283 & $5.0 \%$ & $-1.00[-3.29,1.29]$ & & \\
\hline Lee 2007 & 136.2 & 16.7 & 91 & 143.6 & 15.3 & 93 & $3.0 \%$ & $-7.40[-12.03,-2.77]$ & - & \\
\hline Ma 2014 & 141.81 & 20.34 & 54 & 146.73 & 19.83 & 52 & $1.6 \%$ & $-4.92[-12.57,2.73]$ & & - \\
\hline Tonstad 2007 & 147 & 9 & 29 & 143 & 10 & 16 & $2.3 \%$ & $4.00[-1.89,9.89]$ & & \\
\hline Wakefield 2011 & 133.08 & 16.17 & 73 & 137.34 & 16.32 & 94 & $2.8 \%$ & $-4.26[-9.22,0.70]$ & & \\
\hline Woollard 1995 & 131 & 16.84 & 46 & 138 & 16.36 & 48 & $1.9 \%$ & $-7.00[-13.72,-0.28]$ & 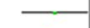 & \\
\hline Zabler 2018 & 126.22 & 18.69 & 29 & 134.88 & 16.65 & 30 & $1.2 \%$ & $-8.66[-17.70,0.38]$ & - & \\
\hline Zhu 2017 & 139.18 & 17.66 & 67 & 140.43 & 22.69 & 67 & $1.8 \%$ & $-1.25[-8.13,5.63]$ & & \\
\hline Subtotal $(95 \% \mathrm{Cl})$ & & & 2016 & & & 1809 & $42.4 \%$ & $-3.38[-4.79,-1.98]$ & $\bullet$ & \\
\hline $\begin{array}{l}\text { Heterogeneity. } \mathrm{Tau}^{2}= \\
\text { Test for overall effect. }\end{array}$ & $\begin{array}{l}2.23 ; \mathrm{Chi}^{2} \\
\mathrm{Z}=4.72\langle\mathrm{P}\end{array}$ & $\begin{array}{l}z=19.89, d \\
P<0.0000\end{array}$ & $\begin{array}{l}d f=13( \\
01)\end{array}$ & $(P=0.10$ & $0 ; i^{2}=35 \%$ & & & & & \\
\hline 4.13.3 Physician and & provider & & & & & & & & & \\
\hline Hennessy 2006 & 131 & 16.8 & 552 & 133 & 17.1 & 541 & $5.3 \%$ & $-2.00[-4.01,0.01]$ & -1 & \\
\hline Hunt 2004 & 135 & 14.7 & 162 & 137 & 15.4 & 150 & $4.0 \%$ & $-2.00[-5.35,1.35]$ & $\rightarrow$ & \\
\hline Lang 1995 & 150.5 & 16.17 & 37 & 154.2 & 16.32 & 34 & $1.6 \%$ & $-3.70[-11.27,3.87]$ & & \\
\hline Roumie 2006 & 138.41 & 17.67 & 280 & 145.04 & 19.15 & 199 & $4.0 \%$ & $-6.63[-10.00,-3.26]$ & - & \\
\hline Stewart 2005 & 142 & 16 & 38 & 144 & 20 & 36 & $1.4 \%$ & $-2.00[-10.28,6.28]$ & & \\
\hline Subtotal $(95 \% \mathrm{Cl})$ & & & 1069 & & & 960 & $16.3 \%$ & $-3.21[-5.26,-1.16]$ & $\bullet$ & \\
\hline $\begin{array}{l}\text { Heterogeneity: Tau }= \\
\text { Test for overall effect: }\end{array}$ & $\begin{array}{l}1.66 ; \mathrm{Chi}^{2} \\
\mathrm{Z}=3.07\langle\mathrm{P}\end{array}$ & $\begin{array}{l}=5.83, \mathrm{df} \\
P=0.002)\end{array}$ & $f=4(P=$ & $=0.21): \mathrm{H}^{\prime}$ & $F^{2}=31 \%$ & & & & & \\
\hline 4.13.4 Team & & & & & & & & & & \\
\hline Hunt 2008 & 137 & 17 & 142 & 143 & 18 & 130 & $3.4 \%$ & $-6.00[-10.17,-1.83]$ & - & \\
\hline McLean 2008 & 132.4 & 16.17 & 115 & 134.9 & 16.32 & 112 & $3.3 \%$ & $-2.50[-6.73,1.73]$ & $\longrightarrow$ & \\
\hline Tobari 2010 & 132.1 & 22.24 & 64 & 133.8 & 22.4 & 64 & $1.6 \%$ & $-1.70[-9.43,6.03]$ & & \\
\hline Subtotal $(95 \% \mathrm{Cl})$ & & & 321 & & & 306 & $8.2 \%$ & $-3.94[-6.71,-1.17]$ & 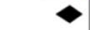 & \\
\hline $\begin{array}{l}\text { Heterogeneity: } \text { Tau }^{2}= \\
\text { Test for overall effect. }\end{array}$ & $\begin{array}{l}0.00 ; \mathrm{Chi}^{2} \\
\mathrm{Z}=2.79(\mathrm{P}\end{array}$ & $\begin{array}{l}=1.71, d f \\
P=0.005)\end{array}$ & $f=2(P=$ & $=0.43) ;$ & $F^{2}=0 \%$ & & & & & \\
\hline Total $(95 \% \mathrm{Cl})$ & & & 4435 & & & 4116 & $100.0 \%$ & $-4.41[-5.52,-3.30]$ & 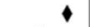 & \\
\hline $\begin{array}{l}\text { Heterogeneity. } \mathrm{Tau}^{2}= \\
\text { Test for overall effect }\end{array}$ & $\begin{array}{l}5.05 ; \mathrm{Cni}^{2} \\
\mathrm{Z}=7.77 \text { (P }\end{array}$ & $\begin{array}{l}=71.68, d \\
P<0.0000\end{array}$ & $\begin{array}{l}d f=33( \\
01) \\
0 . d f=3\end{array}$ & (P & $01) ; i^{2}=5$ & & & & $\begin{array}{l}-10 \\
\text { erimental] }\end{array}$ & $\begin{array}{l}010 \\
j \text { Favours }\end{array}$ \\
\hline
\end{tabular}

Fig. 4 Subgroup analyses of the effect of interventions by different healthcare professionals. Forest plot shoes difference in systolic blood pressure change after interventions provided by different healthcare professionals individually (pharmacist, nurse or physician) or team, consisting of different healthcare professionals; forest plot was created using RevMan 5.4; Cl - confidence interval, SD - standard deviation; small green squares represent difference in SBP reduction of individual RCTs, horizontal lines show 95\% Cl, black diamonds represent difference in SBP reduction within subgroup and total. No statistically significant difference was found between subgroups

Table 3 The overview of subgroup analyses of the effect of interventions on SBP

\begin{tabular}{|c|c|c|c|}
\hline \multirow{2}{*}{$\begin{array}{l}\text { Subgroups } \\
\text { Duration of intervention }\end{array}$} & \multicolumn{2}{|c|}{ Mean difference SBP mmHg $(95 \% \mathrm{Cl})$} & \multirow[t]{2}{*}{$P$ value } \\
\hline & 6 months and under & Over 6 months & \\
\hline & $-4.34(-6.13$ to -2.54$)$ & $-4.58(-5.94$ to -3.22$)$ & $P=0.83$ \\
\hline \multirow[t]{2}{*}{ Place of blood pressure measurement } & Home & Physician's office/clinic & \\
\hline & $-2.85(-4.66$ to -1.04$)$ & $-4.50(-5.74$ to -3.26$)$ & $P=0.14$ \\
\hline \multirow[t]{2}{*}{ Tailored intervention } & Tailored & Not tailored & \\
\hline & $-4.40(-7.19$ to -1.60$)$ & $-4.37(-5.58$ to -3.15$)$ & $P=0.99$ \\
\hline \multirow[t]{2}{*}{ Medication adherence improvement techniques } & Used & Not used & \\
\hline & $-4.34(-5.91$ to -2.78$)$ & $-4.48(-6.09,-2.88)$ & $P=0.90$ \\
\hline \multirow[t]{2}{*}{ Referral for medication change or adjustment } & Included & Not included & \\
\hline & $-4.46(-6.21$ to -2.71$)$ & $-4.40(-5.85$ to -2.96$)$ & $P=0.96$ \\
\hline
\end{tabular}

${ }^{1} P$ value shows if the difference in mean difference of SBP between subgroups is statistically significant. E.g., the subgroup difference between interventions that lasted up to 6 months and interventions that lasted over 6 months was not statistically significant, both interventions were effective 
Table 4 The overview of the effect of interventions on BP control

\begin{tabular}{|c|c|c|c|}
\hline Subgroups & OR $(95 \% \mathrm{Cl})$ & & $P$ value $^{2}$ \\
\hline \multirow[t]{2}{*}{ Duration of intervention } & 6 months and under & Over 6 months & \\
\hline & 1.64 (1.24 to 2.16$)$ & 2.14 (1.60 to 2.87$)$ & $P=0.19$ \\
\hline \multirow[t]{2}{*}{ Baseline systolic blood pressure } & Below $150 \mathrm{mmHg}$ & Over $150 \mathrm{mmHg}$ & \\
\hline & $1.51[1.17,1.96]$ & $2.27[1.83,2.81]$ & $P=0.02$ \\
\hline \multirow[t]{2}{*}{ Healthcare provider } & $\begin{array}{l}\text { Single (pharmacist, nurse or physician } \\
\text { alone) }\end{array}$ & Team & \\
\hline & $1.96[1.47,2.62]$ & $1.81[1.38,2.36]$ & $P=0.68$ \\
\hline \multirow[t]{2}{*}{ Tailored intervention } & Tailored & Not tailored & \\
\hline & $1.94(1.16$ to 3.25$)$ & 1.83 (1.44 to 2.32$)$ & $P=0.84$ \\
\hline \multirow[t]{2}{*}{ Medication adherence improvement techniques } & Used & Not used & \\
\hline & 2.35 (1.62 to 3.42$)$ & 1.65 (1.28 to 2.11$)$ & $P=0.12$ \\
\hline \multirow[t]{2}{*}{ Referral for medication change or adjustment } & Included & Not included & \\
\hline & $1.77[1.41,2.21]$ & $2.06[1.34,3.16]$ & $P=0.54$ \\
\hline
\end{tabular}

${ }^{2} P$ value shows if the difference in OR between subgroups is statistically significant. E.g., patients with the initial SBP over $150 \mathrm{mmHg}$ had a higher chance to achieve the BP under control than patients with the initial SBP assessment under $150 \mathrm{mmHg}$ and the difference was statistically significant

used. The potential sources of heterogeneity were explored by conducting subgroup analyses by the type of clinical trial method, the duration of intervention and the type of a healthcare professional performing the intervention. No difference in effect was found. Moreover, sensitivity analyses accounting for an overall assessment of bias and study size reported similar effects on BP. Causes of heterogeneity could be comorbidities, the number of medications or the age of the patients, but the reasons were not identified, as individual patient data would have been required. Differences in terms of interventions, data collection methods and setting may explain the heterogeneity as well.

\section{Comparison with existing literature}

The study results support the idea that the modification of lifestyle is important for lowering blood pressure and managing cardiovascular risk. Results are in line with other systematic reviews on different types of interventions. Internet-based interventions showed to reduce SBP by $3.8 \mathrm{mmHg}$ and DBP by $2.1 \mathrm{mmHg}$ [59] and digital interventions to reduce $\mathrm{SPB}$ by $3.74 \mathrm{mmHg}$ and DBP by $2.37 \mathrm{mmHg}$ [60]. Self-monitoring of hypertension was associated with a significant decline in SBP by $3.96 \mathrm{mmHg}$ and DBP by $1.85 \mathrm{mmHg}$ [61].

All international guidelines recommend non-pharmacological approaches in the early stages of hypertension. In the ACC/AHA 2017 guidelines, interventions on lifestyle modifications have an even greater place in the management of hypertensive patients than in the European guidelines. ACC/AHA 2017 guidelines recommend lifestyle modifications to the patients having 130-139/80$89 \mathrm{mmHg}$ blood pressure, reviewing the effects after 3 or 6 months [62]. Although traditionally interventions on lifestyle modifications are the domain of physicians or nurses, pharmacists could perform those interventions as well. This is in line with the developments to extend the traditional role of pharmacists $[63,64]$.

\section{Implications for research and practice}

As the interventions were complex, the intervention component that had the maximum effect on blood pressure was not singled out. This may suggest the opportunity for future research. Individual patient data meta-analysis could explain the effects of interventions on different patients' groups. Cost effectiveness studies could provide economic assessment of lifestyle interventions.

This systematic review shows that healthcare professional-led interventions on lifestyle modifications lowered elevated blood pressure and a higher percentage of patients had their blood pressure well controlled. The results suggest that healthcare professional-led interventions on lifestyle modifications should be implemented in daily practice. The barriers to implement such interventions include traditional practices and structures; sceptical, stereotypical attitudes from professionals; and factors related to the development of person-centered interventions [65].

\section{Conclusions}

Healthcare professional-led interventions were effective. Patients achieved almost $5 \mathrm{mmHg}$ decrease of SBP and more patients achieved BP control. The results suggest that efforts are needed for widespread implementation.

\section{Abbreviations}

BP: Blood pressure; SBP: Systolic blood pressure; DBP: Diastolic blood pressure; CVD: Cardiovascular desease; Cl: Confidence interval; RCT: Randomized 
clinical trial; cRCT: Cluster randomized clinical trial; ICC: Intracluster correlation coefficient.

\section{Supplementary Information}

The online version contains supplementary material available at https://doi. org/10.1186/s12875-021-01421-z.

Additional file 1. Search strategy. Search terms for PubMed

\section{Acknowledgements}

Not applicable.

\section{Authors' contributions}

All authors contributed to this study. IT and JP searched, pooled and included studies into systematic review. TN build a bias tool for non-pharmacological interventions. IT and TF assessed the biases of included studies. RK helped building a search key and provided with the clinical guidance's on hypertension. MP helped with the statistical part of the research. JG contributed in writing the manuscript. IT and KT analysed the data and were major contributors in writing the manuscript. All authors read and approved the final manuscript.

\section{Funding}

None.

\section{Availability of data and materials}

The datasets used and/or analysed during the current study are available from the corresponding authors on reasonable request.

\section{Declarations}

\section{Ethics approval and consent to participate}

Not applicable.

\section{Consent for publication}

Not applicable.

\section{Competing interests}

The authors declare that they have no competing interests.

\begin{abstract}
Author details
'Unit of PharmacoTherapy, -Epidemiology \&-Economics, Groningen Research Institute of Pharmacy (GRIP), University of Groningen, Groningen, Netherlands. ${ }^{2}$ Pharmacy Center, Faculty of Medicine, Vilnius University, Vilnius, Lithuania. ${ }^{3}$ Department of Health Sciences, University of Groningen, University Medical Center Groningen, Groningen, Netherlands. ${ }^{4}$ Department of Economics, Econometrics \& Finance, Faculty of Economics \& Business, University of Groningen, Groningen, Netherlands. ${ }^{5}$ Pharmacology \& Clinical Pharmacy Department, Can Tho University of Medicine and Pharmacy, Can Tho City, Vietnam. ${ }^{6}$ Lithuanian University of Health Sciences, Kaunas, Lithuania.
\end{abstract}

Received: 4 July 2019 Accepted: 23 March 2021

Published online: 05 April 2021

\section{References}

1. Townsend N, Wilson L, Bhatnagar P, Wickramasinghe K, Rayner M, Nichols M. Cardiovascular disease in Europe 2016: an epidemiological update. Eur Heart J. 2016;37(42):3182-3. https://doi.org/10.1093/eurheartj/ehw468.

2. WHO. Noncommunicable diseases country profiles 2018: WHO; 2018.

3. Benjamin EJ, Blaha MJ, Chiuve SE, Cushman M, Das SR, Deo R, et al. Heart disease and stroke statistics'2017 update: a report from the American Heart Association. Circulation. 2017;135:e146-603 Lippincott Williams and Wilkins.

4. Forouzanfar MH, Liu P, Roth GA, Ng M, Biryukov S, Marczak L, et al. Global burden of hypertension and systolic blood pressure of at least 110 to 115mmHg, 1990-2015. JAMA. 2017;317(2):165-82.
5. Zhang D, Wang G, Zhang P, Fang J, Ayala C. Medical expenditures associated with hypertension in the U.S., 2000-2013. Am J Prev Med. 2017:53(6):S164-71.

6. Kirkland EB, Heincelman M, Bishu KG, Schumann SO, Schreiner A, Axon $\mathrm{RN}$, et al. Trends in healthcare expenditures among US adults with hypertension: National estimates, 2003-2014. J Am Heart Assoc. 2018;7(11). https://doi.org/10.1161/JAHA.118.008731 [cited 2021 Jan 6].

7. Forouzanfar MH, Afshin A, Alexander LT, Biryukov S, Brauer M, Cercy K, et al. Global, regional, and national comparative risk assessment of 79 behavioural, environmental and occupational, and metabolic risks or clusters of risks, 1990-2015: a systematic analysis for the global burden of disease study 2015. Lancet. 2016;388(10053):1659-724.

8. Timmis A, Townsend N, Gale CP, Torbica A, Lettino M, Petersen SE, et al. European society of cardiology: cardiovascular disease statistics 2019. Eur Heart J. 2020;41(1):12-85.

9. 2018 ESC Guidelines for the management of cardiovascular diseases during pregnancy | European Heart Journal | Oxford Academic [Internet]. [cited 2020 Jul 1]. Available from: https://academic.oup.com/eurheartj/ article/39/34/3165/5078465

10. Valenzuela PL, Carrera-Bastos P, Gálvez BG, Ruiz-Hurtado G, Ordovas JM, Ruilope $L M$, et al. Lifestyle interventions for the prevention and treatment of hypertension. Nat Rev Cardiol. 2020:1-25 Nature Research.

11. Piepoli MF, Hoes AW, Agewall S, Albus C, Brotons C, Catapano AL, et al. 2016 European guidelines on cardiovascular disease prevention in clinical practice. Eur Heart J. 2016;37:2315-81 Oxford University Press.

12. Dickinson HO, Mason JM, Nicolson DJ, Campbell F, Beyer FR, Cook JV, et al. Lifestyle interventions to reduce raised blood pressure: a systematic review of randomized controlled trials. J Hypertens. 2006;24(2):215-33 Available from: http://journals.lww.com/00004872-200602000-00002. [cited 2020 Dec 16]

13. Cheema E, Sutcliffe P, Singer DRJ. The impact of interventions by pharmacists in community pharmacies on control of hypertension: a systematic review and meta-analysis of randomized controlled trials. Br J Clin Pharmacol. 2014;78(6):1238-47.

14. Clark CE, Smith LFP, Taylor RS, Campbell JL. Nurse led interventions to improve control of blood pressure in people with hypertension: systematic review and meta-analysis. BMJ. 2010;341:491 BMJ Publishing Group.

15. Rose SA, Poynter PS, Anderson JW, Noar SM, Conigliaro J. Physician weight loss advice and patient weight loss behavior change: a literature review and meta-analysis of survey data. Int J Obes. 2013;37:118-28 Nature Publishing Group.

16. Moher D. Preferred reporting items for systematic reviews and meta-analyses: The PRISMA statement. Ann Intern Med. 2009;151(4):264. https://doi. org/10.7326/0003-4819-151-4-200908180-00135 [cited 2020 Dec 16].

17. Perk J, De Backer G, Gohlke H, Graham I, Reiner Ž, Verschuren M, et al. European Guidelines on cardiovascular disease prevention in clinical practice (version 2012). Eur Heart J. 2012;33:1635-701 Oxford University Press.

18. World Health Organization (2010) Classifying health workers. [cited 2020 Dec 16]. Available from: http://www.who.int/hrh/statistics/Health_worke rs classification.pdf

19. Inthout J, loannidis JPA, Borm GF, Goeman JJ. Small studies are more heterogeneous than large ones: a meta-meta-analysis. J Clin Epidemiol. 2015;68(8):860-9.

20. Higgins JPT, Thomas J, Chandler J, Cumpston M, Li T, Page MJ WV. Cochrane handbook for systematic reviews of interventions version 6.1 (updated September 2020). Cochrane, 2020. [Internet]. Available from: www.training.cochrane.org/handbook.

21. Jakobsen JC, Wetterslev J, Lange T, Gluud C, et al. Cochrane Database Syst Rev. 2016:3:ED000111 Wiley.

22. Artinian NT, Flack JM, Nordstrom CK, Hockman EM, Washington OGM, Jen K-LC, et al. Effects of nurse-managed telemonitoring on blood pressure at 12-month follow-up among Urban African Americans. Nurs Res. 2007;56(5):312-22 Available from: http://journals.Iww.com/00006199200709000-00004 [cited 2020 Dec 16].

23. Borenstein JE, Graber G, Saltiel E, Wallace J, Ryu S, Jackson A, et al. Physician-pharmacist comanagement of hypertension: a randomized, comparative trial. Pharmacotherapy. 2003;23(2):209-16.

24. Little P, Kelly J, Barnett J, Dorward M, Margetts B, Warm D. Randomised controlled factorial trial of dietary advice for patients with a single high blood pressure reading in primary care. Br Med J. 2004;328(7447):1054-7. 
25. Magid DJ, Ho PM, Olson KL, Brand DW, Welch LK, Snow KE, et al. A multimodal blood pressure control intervention in 3 healthcare systems. Am J Manag Care. 2011;17(4):e96-103.

26. Margolis KL, Asche SE, Bergdall AR, Dehmer SP, Groen SE, Kadrmas HM, et al. Effect of home blood pressure telemonitoring and pharmacist management on blood pressure control a cluster randomized clinical trial. JAMA. 2013;310(1):46-56.

27. McKenney JM, Slining JM, Richard Henderson H, Devins D, Barr M. The effect of clinical pharmacy services on patients with essential hypertension. Circulation. 1973;48(5):1104-11.

28. Mehos BM, Saseen JJ, MacLaughlin EJ. Effect of pharmacist intervention and initiation of home blood pressure monitoring in patients with uncontrolled hypertension. Pharmacotherapy. 2000;20(11):1384-9.

29. Roumie CL, Elasy TA, Greevy R, Griffin MR, Liu X, Stone WJ, et al. Improving blood pressure control through provider education, provider alerts, and patient education: a cluster randomized trial. Ann Intern Med. 2006;145(3):165-75.

30. Vivian EM. Improving blood pressure control in a pharmacist-managed hypertension clinic. Pharmacotherapy. 2002;22(12 I):1533-40.

31. Wakefield BJ, Holman JE, Ray A, Scherubel M, Adams MR, Hillis SL, et al. Effectiveness of home telehealth in comorbid diabetes and hypertension: a randomized, controlled trial. Telemed e-Health. 2011;17(4):254-61.

32. Zillich AJ, Sutherland JM, Kumbera PA, Carter BL. Hypertension outcomes through blood pressure monitoring and evaluation by pharmacists (HOME study). J Gen Intern Med. 2005;20(12):1091-6.

33. Zabler B, Tsai PY, Fendrich M, Cho Y, Taani MH, Schiffman R. Effect of a nurse case management intervention for hypertension selfmanagement in low-income African Americans. Contemp Clin Trials. 2018;71:199-204.

34. Bosworth HB, Olsen MK, Grubber JM, Neary AM, Orr MM, Powers BJ, et al. Two self-management interventions to improve hypertension control: a randomized trial. Ann Intern Med. 2009;151(10):687-95.

35. Bosworth HB, Powers BJ, Olsen MK, McCant F, Grubber J, Smith V, et al. Home blood pressure management and improved blood pressure control: results from a randomized controlled trial. Arch Intern Med. 2011;171(13):1173-80.

36. Brennan T, Spettell C, Villagra V, Ofili E, McMahill-Walraven C, Lowy EJ, et al. Disease management to promote blood pressure control among african americans. Popul Health Manag. 2010;13(2):65-72.

37. Green BB, Cook AJ, Ralston JD, Fishman PA, Catz SL, Carlson J, et al. Effectiveness of home blood pressure monitoring, web communication, and pharmacist care on hypertension control: a randomized controlled trial. JAMA. 2008:299(24):2857-67.

38. Hennessy S, Leonard CE, Yang W, Kimmel SE, Townsend RR, Wasserstein $A G$, et al. Effectiveness of a two-part educational intervention to improve hypertension control: a cluster-randomized trial. Pharmacotherapy. 2006;26(9):1342-7. https://doi.org/10.1592/phco.26.9.1342 [cited 2020 Dec 16].

39. Hunt JS, Siemienczuk J, Pape G, Rozenfeld Y, MacKay J, LeBlanc BH, et al. A randomized controlled trial of team-based care: impact of physicianpharmacist collaboration on uncontrolled hypertension. J Gen Intern Med. 2008;23(12):1966-72.

40. Hunt JS, Siemienczuk J, Touchette D, Payne N. Impact of educational mailing on the blood pressure of primary care patients with mild hypertension. J Gen Intern Med. 2004;19(9):925-30.

41. Johnson W, Shaya FT, Khanna N, Warrington VO, Rose VA, Yan X, et al. The Baltimore partnership to educate and achieve control of hypertension (the BPTEACH trial): a randomized trial of the effect of education on improving blood pressure control in a largely African American population. J Clin Hypertens. 2011;13(8):563-70.

42. Kastarinen MJ, Puska PM, Korhonen MH, Mustonen JN, Salomaa WV Sundvall JE, et al. Non-pharmacological treatment of hypertension in primary health care: a 2-year open randomized controlled trial of lifestyle intervention against hypertension in eastern Finland. J Hypertens. 2002;20(12):2505-12.

43. Lang T, Nicaud V, Darné B, Rueff B. Improving hypertension control among excessive alcohol drinkers: a randomized controlled trial in France. J Epidemiol Community Health. 1995;49(6):610-6.
44. Morgado M, Rolo S, Castelo-Branco M. Pharmacist intervention program to enhance hypertension control: a randomised controlled trial. Int J Clin Pharm. 2011:33(1):132-40.

45. Tonstad S, Alm CS, Sandvik E. Effect of nurse counselling on metabolic risk factors in patients with mild hypertension: a randomised controlled trial. Eur J Cardiovasc Nurs. 2007;6(2):160-4.

46. Zhu X, Wong FKY, Wu CLH. Development and evaluation of a nurse-led hypertension management model: a randomized controlled trial. Int J Nurs Stud. 2018:77:171-8.

47. Ma C, Zhou Y, Zhou W, Huang C. Evaluation of the effect of motivational interviewing counselling on hypertension care. Patient Educ Couns. 2014:95(2):231-7.

48. McLean DL, McAlister FA, Johnson JA, King KM, Makowsky MJ, Jones $\mathrm{CA}$, et al. A randomized trial of the effect of community pharmacist and nurse care on improving blood pressure management in patients with diabetes mellitus: study of cardiovascular risk intervention by pharmacists-hypertension (SCRIP-HTN). Arch Intern Med. 2008;168(21):2355-61.

49. Woollard J, Beilin L, Lord T, Puddey I, MacAdam D, Rouse I. A controlled trial of nurse counselling on lifestyle change for hypertensives treated in general practice: preliminary results. Clin Exp Pharmacol Physiol. 1995;22(6-7):466-8.

50. Garcia-Peña C, Thorogood M, Armstrong B, Reyes-Frausto S, Muñoz O. Pragmatic randomized trial of home visits by a nurse to elderly people with hypertension in Mexico. Int J Epidemiol. 2001;30(6):1485-91.

51. Lee LL, Arthur A, Avis M. Evaluating a community-based walking intervention for hypertensive older people in Taiwan: a randomized controlled trial. Prev Med. 2007;44(2):160-6.

52. Saleem F, Hassali MA, Shafie AA, UI Haq N, Farooqui M, Aljadhay H, et al. Pharmacist intervention in improving hypertension-related knowledge, treatment medication adherence and health-related quality of life: a non-clinical randomized controlled trial. Health Expect. 2015;18(5):1270-81.

53. Sookaneknun P, Richards RME, Sanguansermsri J, Teerasut C. Pharmacist involvement in primary care improves hypertensive patient clinical outcomes. Ann Pharmacother. 2004;38:2023-8.

54. Stewart A, Noakes T, Eales C, Shepard K, Becker P, Veriawa Y. Adherence to cardiovascular risk factor modification in patients with hypertension. Cardiovasc J S Afr. 2005;16(2):102-7.

55. Tobari H, Arimoto T, Shimojo N, Yuhara K, Noda H, Yamagishi K, et al. Physician-pharmacist cooperation program for blood pressure control in patients with hypertension: a randomized-controlled trial. Am J Hypertens. 2010;23(10):1144-52.

56. Wal P, Wal A, Bhandari A, Pandey U, Rai A. Pharmacist involvement in the patient care improves outcome in hypertension patients. J Res Pharm Pract. 2013:2(3):123.

57. Grossman E. Blood pressure: the lower, the better: the con side. Diabetes Care. 2011;34:S308-12 American Diabetes Association.

58. Stamler J, Rose G, Stamler R, Elliott P, Dyer A, Marmot M. INTERSALT study findings. Public health and medical care implications. Hypertension. 1989;14(5):570-7.

59. Liu S, Dunford SD, Leung YW, Brooks D, Thomas SG, Eysenbach G, et al. Reducing blood pressure with internet-based interventions: a meta-analysis. Can J Cardiol. 2013;29:613-21 Canadian Journal of Cardiology.

60. McLean G, Band R, Saunderson K, Hanlon P, Murray E, Little P, et al. Digital interventions to promote self-management in adults with hypertension systematic review and meta-analysis. J Hypertens. 2016;34:600-12 Lippincott Williams and Wilkins.

61. Li R, Liang N, Bu F, Hesketh T. The effectiveness of self-management of hypertension in adults using mobile health: systematic review and metaanalysis. J Med Internet Res. 2020;22:e17776.

62. Whelton PK, Carey RM, Aronow WS, Casey DE, Collins KJ, Himmelfarb CD, et al. 2017 ACC/AHA/AAPA/ABC/ACPM/AGS/APhA/ASH/ASPC/ NMA/PCNA guideline for the prevention, detection, evaluation, and management of high blood pressure in adults a report of the American College of Cardiology/American Heart Association Task Force on clinical practice guidelines. Hypertension. 2018;71:E13-115 Lippincott Williams and Wilkins. 
63. Mes MA, Katzer CB, Chan AHY, Wileman V, Taylor SJC, Horne R. Pharmacists and medication adherence in asthma: a systematic review and meta-analysis. Eur Respir J. 2018;52 European Respiratory Society.

64. van Eikenhorst L, Taxis K, van Dijk L, de Gier H. Pharmacist-led selfmanagement interventions to improve diabetes outcomes. A systematic literature review and meta-analysis. Front Pharmacol. 2017;8 Frontiers Media S.A.

65. Moore L, Britten N, Lydahl D, Naldemirci Ö, Elam M, Wolf A. Barriers and facilitators to the implementation of person-centred care in different healthcare contexts. Scand J Caring Sci. 2017;31(4):662-73. https://doi. org/10.1111/scs.12376 [cited 2020 Dec 16].

\section{Publisher's Note}

Springer Nature remains neutral with regard to jurisdictional claims in published maps and institutional affiliations.

- fast, convenient online submission

- thorough peer review by experienced researchers in your field

- rapid publication on acceptance

- support for research data, including large and complex data types

- gold Open Access which fosters wider collaboration and increased citations

- maximum visibility for your research: over $100 \mathrm{M}$ website views per year

At BMC, research is always in progress.

Learn more biomedcentral.com/submissions 